\title{
The Impact of Mobile Phone Technology on Agricultural Extension Services Delivery: Evidence from India
}

\begin{abstract}
This study examines the impact of mobile phone enhanced intervention in agricultural extension service delivery in India. Findings show that the amount, quality and speed of service delivery, have improved significantly because of the intervention. There are also benefits in terms of greater knowledge and awareness of new agriculture practice, farmers' aspiration to try new technology in the future and access to credit. The system does not discriminate farmers from disadvantaged and low education backgrounds. Thus, a system of well-used technology, which is assisted by trained village youths can serve as a tool for inclusive development.
\end{abstract}

Key words: Mobile phone technology, agricultural extension services, impact evaluation, India 


\section{Introduction}

Smallholder farmers, who dominate the landscape of the developing world, require adequate access to knowledge, information, and other necessary services to improve farming. It is crucial to endow farmers with the required knowledge and services in a quality and timely way. Farmers in remote villages are excluded due to a lack of infrastructure (United Nations, 2005). Agricultural extension services serve as an important tool to transfer knowledge, advise and educate farmers about new technology and practices, and stimulate desirable agricultural developments (Anderson \& Feder, 2004). Farmers often use sub-optimal agricultural practices due to lack of information, knowledge and inputs and their management (Jack, 2011). In India, the majority of resource-poor farmers have restricted access to state-funded services; nearly 60 per cent are beyond access (Ferroni \& Zhou, 2012).

Extension workers need timely gathering and dissemination of a broad range of information for small producers. Farmers have a real need to access market information (Ogutu, Okello, \& Otieno, 2014), land records, farm management information, and knowledge on management of pests and diseases, pesticides use and management (Cole \& Fernando, 2012). In this regard, information and communication technology (ICT) can play a key role (Aker, 2011). However, ICT is not fully utilised in agriculture (Meera, Jhamtani, \& Rao, 2004). Poor and marginalised farmers, females, and marginal areas, are all excluded. Farmers need appropriate ICTs to be able to use and improve their knowledge about farm practices.

The unprecedented growth of mobile phone in rural areas of developing countries, reaching 70 per cent at the end of 2010 (ITU, 2011), has raised the expectations about its potential contributions to timely high-quality extension service delivery. Can mobile phone technology help farmers gain agricultural knowledge and information promptly? Has it been effective in delivering extension services as expected? What is its wider impact on farmers' attitudes to new agricultural technology in 
the future? These are important questions that have not yet been fully explored. The assessment method of existing evaluation studies is often subject to serious selection bias (Heeks \& Molla, 2009).

Farmers can receive information through radio, television and satellite-based systems but cannot voice their own problems directly to experts for a solution. Mobile phones having both audio and video functions can meet most of the basic needs of the poor and allow for two-way communication between farmers and service providers (Aker, 2011). Many initiatives with mobile phones are emerging, but most of them use voice, SMS and internet-based services (Mehta, 2013; Ogutu et al., 2014). Mobile phones save time and costs required to corroborate price information with multiple sources reducing grain price dispersion across markets and seasons (Cole \& Fernando, 2012). Fishermen learnt about prices across locations and decided where to sell their products profitably (Jensen, 2007). Farmers also experienced reduced price dispersion, volatility and transaction costs (Lee \& Bellemare, 2013; Zanello, Srinivasan, \& Shankar, 2014).

Cole and Fernando (2012) evaluate the impact of agriculture consulting services (called AO) comprising an automated voice message sent once in a week to selected farmers. However, their research focuses on beneficiaries who are cash crop producers and must own a mobile phone. These two criteria excluded the most disadvantaged farmers. Moreover, their randomised design within the same village raises the possibility of spillovers from treatment to control group. This project delivered a unified push-content to all the mobile phone owners in the programme. Though recipients gain information through voice messages, they cannot convey their immediate needs. Therefore, the effectiveness of the service will be different from those providing responsive extension services.

Fafchamps and Minten (2012) estimate the gains from SMS messages on market and weather information delivered to farmers' mobile phones. They found that treatment affected spatial arbitrage and crop grading, but the magnitude of the effect was small. Similar to the AO project, farmers benefiting from this service had mobile phones without the provision of making videos. Video images 
would be useful to present the problems correctly to advisers because farmers often find it difficult to describe problems in their own language. With push messages to mobile phones, farmers are only receivers.

The Digital Green in India, an innovative video communication system, combined technology with social organisations to improve the cost-effectiveness of existing agricultural extension (Digital Green, 2011). To the best of our knowledge, independent evaluation of the system was not carried out.

We are still uninformed about the usefulness and timeliness of the advice and the answers to the questions we raised about the changes in accessibility and quality of services, their subsequent impact on farmers' agricultural knowledge and capabilities. In addition, future aspiration is another important under-researched area in development studies. The role of aspirations in triggering efforts for change is being recognised as an emerging frontier of development research (Bernard, Dercon, Orkin \& Taffesse, 2014), but is yet to be explored. Our research provides pioneering evidence, which contributes to fill this gap.

This research is based on an evaluation of an action research project known as 'Knowledge Help Extension Technology Initiative' (KHETI) in India. KHETI has a village assistant called Munna who is pretty tech-savvy and capable of teaching farmers the principles behind new farming practices in a friendly manner. Additionally, KHETI features a two-way interactive system with a multi-media function in the mobile phone incorporating video, voice and SMS messaging. This is a groundbreaking initiative. This paper thus contributes to the literature by adding empirical evidence about the impact of a pioneering mobile phone technology on agricultural extension services transmission. Different from the interventions analysed in the literature (Cole \& Fernando, 2012; Fafchamps \& Minten, 2012), our subject is marginalised farmers in remote areas and hence our analysis may be more generalisable for these communities. 
The remainder of this paper is organised as follows. Section 2 includes the background of the study including the context in India. Section 3 explains the methodology including evaluation design, data collection approach, impact indicators and analytical framework. Section 4 presents the results. Section 5 concludes.

\section{Background}

India has been experiencing major changes in agricultural extension systems since the 1990s (Raabe, 2008). The demand for extension services exceeds the supply. The supply side measures include civil service and public expenditure reform, training and capacity building, public-private partnership and utilisation of ICT. Examples of initiatives are the public sector Diversified Agricultural Support Project and the National Agricultural Technology Project, and the private sector e-Choupal initiative (Rabbe, 2008; Goyal, 2010). E-Choupal involves installation of computers with Internet access in rural areas. The public sector programmes have many constraints including poor communication, limited capacity and the lack of access to sufficient funds. The inclusion of smallholders in remote areas is extremely restricted without a speedy technology.

The Department of Telecommunications in India recorded a penetration rate of wireless telephones at 30.2 per cent in 2008, which was 48 per cent higher than the previous year. In rural India, especially in poorer states such as Madhya Pradesh, mobile phones were not popular in 2008, and noone had a smartphone. Even in 2012 when India had 70 per cent mobile phone users, smartphone penetration was still the lowest among middle-income countries (World Bank, 2012). A few initiatives used ICT to enhance agricultural extension services, but the disadvantaged farmers remain out of range.

\section{The KHETI project}

The KHETI system comprises village assistants called Munnas who use smartphones to create Short Dialogue Strips (SDSs) to facilitate communication between small/marginal farmers and 
agriculture experts (Rizvi \& Dearden, 2010; Appendix 1 includes further details). SDSs are audiovisual creations on local agriculture issues and knowledge. This demand-driven innovative mobile phone-based information system provides a means to exchange multi-media messages. Farmers demanded timely and quality services but the provision was significantly constrained by physical distances with agriculture experts. Other studies also identified similar problems (Ferroni \& Zhou, 2012).

A cooperative-type NGO called the Sironj Crop Producers Company Private Limited (SCPCL) piloted the KHETI. SCPCL was located in Sironj Block (sub-district) of Vidisha district of Madhya Pradesh (MP) in Central India. SCPCL members have limited access to assets. Villages have poor infrastructures. The main crops are wheat, gram and maize in the winter and soybean in the rainy season. Prior to the innovation, SCPCL provided its members with information and services, similar to KHETI, but had difficulty reaching all members in a timely manner. Figure 1 shows how the KHETI system works.

\section{[Insert Figure 1]}

KHETI is more innovative compared to the AO project because farmers are able to show the videos of their problem, for example, a pest attack, to the experts and receive better solutions. Munnas act as carriers of mobile phones and help clients making videos.

KHETI is expected to bring about impact on outcomes in three steps. First, the usage, speed, and quality of agricultural extension services would improve. Second, the greater amount, better quality, and speedily delivered agricultural services would improve farmers' knowledge and capabilities. Third, knowledge and capabilities are expected to be translated to agricultural outputs, income, and welfare. In each step, there are many critical factors in play. If the services are of required quality, farmers are likely to use them to bring desired changes, but this may be affected by the critical 
factors. These links between the intervention and outcomes can be explained using a theory of change. Why we would expect improvement in the productivity of farmers or the ways of their livings? How are these changes expected to occur? KHETI is demand-driven and so farmers are assumed to have the capacity to absorb the information. If the constraints of using the services are removed then the causal chain should operate; farmers would use the services to bring desired changes.

\section{Methodology}

\subsection{Evaluation design}

We have used a quasi-experimental design; all 698 SCPCL members from 30 villages and 507 non-members from 26 non-SCPCL villages were interviewed. Two surveys were carried out; the first in July 2008 is the baseline, the intervention was started in August 2008; and the next follow-up survey was carried out in March 2009, approximately eight months after the intervention.

Both surveys used a structured questionnaire. Trained local survey assistants filled in the translated local language version of the questionnaire. The control group was chosen purposely from non-SCPCL villages to minimise the knowledge spillovers. Due to multifarious constraints such as limited time, unfavourable climate and limited resources, a smaller than the planned control sample of farmers were interviewed. This sample was selected as follows.

Of 225 villages, 150 had no SCPCL or any other NGO interventions. From these villages, 26 were selected randomly; around 18 per cent of the non-SCPCL villages in the block. From each nonSCPCL village, up to 25 households were chosen randomly or completely. The villages of Sironj are small. Either 'all matching households' from the small villages were included or from relatively larger villages ' 25 households' were chosen at random. The groups match in terms of major characteristics ${ }^{1}$.

We compare various service provision and outcome indicators between three groups: SCPCL members who adopted KHETI, SCPCL members who did not adopt KHETI (control group 2), and 
non-members who receive no regular agricultural extension services (control group 1). In order to disentangle the effect of ICT, it is important to compare farmers who receive regular SCPCL extension services and those with KHETI-embedded SCPCL extension services. All SCPCL members were eligible to benefit from the KHETI services, but a small number in 6 SCPCL-involved villages reported that they did not adopt the Munnas' services. This becomes a de-facto control group 2 for the treatment group. In fact, this may be a better control group because this group received SCPCL services before and was more likely to share common trend with the treated group.

The study used a difference-in-difference design; both treated and control groups were interviewed before the intervention with a follow-up. In our quasi-experiment, like other social experiments, it is not possible to control for all characteristics that may systematically influence outcome variables. We used the baseline survey to generate control variables and to facilitate checking the likely differences of our sample from an appropriately implemented randomisation (Duflo, Glennerster, \& Kremer, 2008) ${ }^{2}$. We used regression analysis to minimise the sample selection bias. We also examined the sensitivity of regression results by using smaller comparable sub-samples, the type and quality of information provided.

\subsection{Data description}

Some important characteristics of the sample at the baseline are presented in Table 1. The treatment and the control groups are statistically the same in terms of the major characteristics like assets, family income, own land, education, age, and occupation. However, we found some significant differences, for example owning a mobile phone and gender. Only 10 per cent of all the households had mobile phones at the time and so differences are not surprising. Though all in the small/marginal class are eligible for SCPCL membership, those have mobile phones might be informed earlier to get it. The sample appears to be biased towards males. This reflects the Indian context, where men are 
culturally responsible for farming. These differences justify a treatment effects model to correct the sample selection bias.

\section{[INSERT Table 1 HERE]}

\subsection{Impact indicators}

Following Rubin (1974) and Ravallion (2008), we measure impact as follows:

$$
\bar{I}=\frac{1}{n} \sum_{i=1}^{n}\left(O_{i}^{T}-O_{i}^{C}\right)
$$

where $I$ is "impact", $O$ is the value of the interpretable impact indicator, $T$ and $C$ represent treatment group and control group respectively, $i$ represents the sample units (households) and $\mathrm{n}$ is the sample size.

We focus on the indicators such as the changes in quantity and quality of usage of extension services, usefulness, speed and gain on agricultural knowledge. We also examined the change in attitude and aspiration of farmers due to KHETI. Productivity has been used as a common measure of impact, but we focus on other under-researched dimensions of rural development for the following reasons.

First, many dimensions of rural development may be reflected not only in terms of improvements in 'farm productivity/income' but also in farmers' capabilities. Enhanced knowledge and capabilities have much broader relevance and application in modern society (Sen, 1989). Since knowledge is an essential precondition to any kind of future impact, we have indicated enhanced capabilities through the additional quantity and quality of knowledge that farmers gain from KHETI. Also, the familiarity with a new technology signifies an awareness of a broader choice set. Experimenting or observing any new technology implies a certain degree of active engagement that is a valid engagement in itself. Gaining knowledge on new practices, farmers would choose the best alternative from their choice bundle. 
Second, the literature provides robust evidences for greater capabilities/knowledge/education leading to higher productivity, reducing efficiency losses and raising farm incomes (Hayami \& Ruttan, 1970; Phillips, 1994; Foster \& Rosenzweig, 1995; Smith, Gemma \& Palinisami, 2011; Reimers \& Klasen, 2013). The growth literature suggests knowledge/human capital as a driver of economic development (Solow, 1957; Romer, 1990; Aghion \& Howitt, 1992). Farmers Field School experience shows that productivity is directly related to knowledge score on farm practices (Godtland, Sadoulet, de Janvry, Murgai, \& Ortiz, 2004). Current empirical research is limited but supports a positive knowledge-productivity nexus (Bernard et al., 2014). Kijima, Ito and Otsuka (2012) found that training of farmers on improved cultivation practices enhanced the adoption improving productivity.

Third, we have evaluated the impact of this intervention on farmers' aspirations to try new technology for agricultural production in future. Having low aspirations of their future opportunities means that poor people may ignore some potentially beneficial options for investment (Bernard et al., 2014). If constraints are lifted, farmers may aspire to develop more productive practices and new ways of living.

Finally, we discussed earlier that farmers are expected to have the absorptive capacity. The process is supportive involving farmers, village assistants with a smartphone enhanced communication system and agriculture experts. However, extra care would always be necessary to train and employ Munnas so that they are continuously available and capable of providing trusted quality service.

So it is plausible to assume that the gain in knowledge of agricultural issues and changes in attitudes, skills and aspirations would lead to changes in the application of practices which would in turn translate into long-term impact. In addition, we present impact on a material indicator, access to credit.

Knowledge, awareness, and aspirations have no rigid definitions and are difficult, but not impossible to measure. Erbaugh, Donermeyer, and Kibwika (2001) measured farmers' knowledge 
about integrated pest management using an index constructed from rated attributes. Farmers Field School curricula often have been designed to enhance farmers' social and political capabilities in addition to technical skills (van den Berg \& Jiggins, 2007). KHETI was designed such that farmers can get a broad range of information on time, with adequate speed and quality. Therefore we distinguish the effect of KHETI between the effect on extension delivery and beneficiary outcomes. We would expect an impact on delivery (immediate gains from the initiative on the quantity, speed and quality of services delivery); and impact on beneficiaries' knowledge and awareness of agricultural practices and technical know-how as well as their aspirations towards trying new technology in the future.

\subsection{Impact on beneficiaries and on delivery}

Access and knowledge were conceptualised as follows. Farmers were asked firstly, to rate their main constraints and secondly, whether and to what extent these constraints have been reduced since the introduction of the mobile supported Munna services. The four attributes of the main constraints include 1) general agricultural knowledge, 2) new production practices /technology, 3) funding for basic agricultural activities, and 4) funding to use some agricultural knowledge or practices, on a scale of 0 to 5; 0 indicated no importance and 5 indicated high importance. The inverse value of the scores of these attributes is used to construct an awareness-knowledge index (AKI). Farmers were allowed to answer the related questions from self-perception. We assume that their cognitive ability is similar because they belong to the same sub-district. Details of the questions to construct the index are given in Appendix 2 (Table A1). AKI considers equal weight to each attribute as follows.

$$
O_{i}=\frac{\sum_{j=1}^{J} O_{i j}}{S}
$$

Here, $O$ is outcome in general, $i$ represents sampling units, $j=1, \ldots, \mathrm{J} . \quad J$ is the total of component attributes. The constraint scores are converted into knowledge and awareness scores by 
reversing the scores for each attribute, e.g., 0 constraints equals to fully aware (5), in the estimation. $S$ is the maximum limit of scores a farmer can have. So AKI ranges from 0 (indicates no access/knowledge) to 1 (maximum possible access/knowledge).

To reveal the differentiated impact of KHETI on different areas of knowledge and awareness, we also report the estimated results for each indicator. This is certainly an effective way of testing the impact of the intervention; we are likely to observe a significant increase in knowledge and awareness in areas corresponding to effective extension services.

The surveys included some questions related to impact on delivery such as speed, quality and quantity. We constructed a quality index (QI) indicator to measure impact using the same formula and a quality related question, details of which are given in Appendix 2 (Table A1) using the same method as in equation (2).

\subsection{Empirical estimation strategy}

In the difference-in-difference framework, we compute a simple difference specification as follows:

$$
O_{i t}=\alpha+\beta_{1} K_{i}+\beta_{2} N K_{i}+\lambda \text { Post }_{t}+\gamma_{1}\left(\text { Post }^{*} K\right)_{i t}+\gamma_{2}\left(\text { Post }^{*} N K\right)_{i t}+u_{i}
$$

Where, $O_{i}$ is difference in outcome before and after the KHETI intervention, $K_{i v}$ is an indicator variable that takes on the value 1 for a SCPCL member household, $i$, who used the KHETI services (the treatment group) and 0 for being in the control group. $N K_{i v}$ is an indicator variable that equals 1 for a SCPCL member household, $i$, who did not use the KHETI service (treatment group 2) and 0 for the rest. Therefore, the control group consisting of the farmers selected from non-SCPCL villages is the base group in the regression. Post is a dummy variable that equals 1 if the observation was collected after the implementation of the intervention and 0 if it was collected during the baseline; $u_{i}$ is random error with usual properties. $\left(K^{*} \text { Post }\right)_{i t}$ is the interaction of $K$ and Post, and so is (NK*Post). 
Therefore, we can interpret $\gamma_{1}$ as the impact of KHETI when comparing the treatment and control group, and in fact, $\left(\gamma_{1}-\gamma_{2}\right)$ as a more accurate estimation of the impact of KHETI since we are comparing the differences in the changes of the outcome variable between the treatment group and control group 2. A Wald test with the null hypothesis being $\gamma_{1}=\gamma_{2}$ was carried out to testify whether the difference is statistically significant.

We use a multiple regression analysis controlling for other household and village specific effects as follows ${ }^{3}$ :

$$
O_{i v t}=\alpha+\beta_{1} K_{i v}+\beta_{2} N K_{i v}+\lambda \text { Post }_{t}+\gamma_{1}\left(\text { Post }^{*} K\right)_{i v t}+\gamma_{2}\left(\text { Post }^{*} N K\right)_{i v t}+\beta X_{i v t}+\partial V_{v t}+u_{i}
$$

Where $X_{i}$ is a vector of farmer specific characteristics variables; $V_{i}$ is a vector of village specific factors. These variables are chosen based on the common practice of rigorous impact studies as well as parsimony. Definition and descriptive statistics of the variables are reported in Appendix 2 (Table A2). As non-members are located in different villages, we would expect a low spillover effect, but a significant sample selection bias. Farmers in control group 2 chose not to use the KHETI services and the average level of agriculture knowledge of this group is significantly higher than that of the treatment group. We therefore use the Treatment Model for estimation to control for this bias. The estimated Lambda statistics verified that the Treatment Model is preferred to the OLS estimates. Nevertheless, we also report the OLS estimates for a robustness check. Given the nature of the variation in the data, we report results with standard errors clustered at the village level.

With regard to the change in quality between pre- and post-intervention services, we use a reflexive comparison because questions on quality changes were not applicable to the non-treated units. So changes in quality are evaluated using the following model.

$$
Q_{i v t}=\alpha_{2}+\vartheta_{1} \operatorname{Post}_{i v t}+\vartheta_{2} \operatorname{Post}_{N} K_{i v t}+\varphi X_{i v t}+\partial V_{v t}+u_{i}
$$

Where $Q_{i}$ is quality of the extension services, $X_{i}$ is a vector of farmer-specific characteristics variables; $V_{i}$ is a vector of village specific factors, and $u_{i}$ is random error with usual properties. PostK 
is a dummy variable that equals 1 if the observation is collected for the treatment group after the implementation KHETI and 0 otherwise; PostNK is a dummy variable that equals 1 if the observation is collected for control group 2 after the implementation of KHETI and 0 otherwise. Therefore, baseline observations are the base group in this regression analysis. Hence $\left(\vartheta_{1}-\vartheta_{2}\right)$ can be interpreted as the impact of KHETI; $\vartheta_{1}$ can be interpreted as the overall improvement in the quality of services.

\section{Results}

\subsection{The effect of ICT intervention on extension services delivery: speed, quality and quantity}

The majority rated the new technology useful, faster and of better quality (Appendix 2 Table A3) than they had before the intervention. Farmers were using more services than they did before the intervention. The average estimated QI increased from 0.57 to 0.92 (61\% higher). In general, the impact of the technology was prominent in quality of extension services.

We further assessed the impact on service quality while controlling for farmer- and villagespecific characteristics, and took all possible measures to obtain reliable results in Table 2 . We use a Tobit model for estimation because OLS may not produce consistent estimates for the censored dependent variable, QI, ranging from 0 to 1 (Cameron \& Trivedi, 2009). Nevertheless, we report OLS results for a robustness check. Regression specification error test (RESET) suggests that there is no significant error in the model specification, but a significant heteroskedasticity was detected. ${ }^{4}$ White heteroskedasticity-robust standard errors are clustered at the village level. The estimated effect of KHETI on the quality of services is positive and highly significant. We also observed an improvement in service quality for control group 2. The magnitude of the estimated coefficient is 0.435 for SCPCL members who used KHETI, which is about 0.06 units $(14 \%)$ higher than that of the 'member not used KHETI' variable. Results of the Wald test of the null hypothesis that the two estimated coefficients 
equal to each other suggest that the difference between them is significant. Therefore, consistent and robust results indicate a positive impact of KHETI on the quality of the extension services.

Land rental and access to irrigation facilities affect the quality of the extension services negatively. Those renting might have put less effort to obtain quality extension input due to disincentives arising from sharing or leasing arrangements. Those renting out are not directly involved in the cultivation and so might not connect with extension agents. Farmers with irrigation facilities are expected to be more aware of improved practices and might have access to relatively better extension services before the introduction of ICT enhanced services. Farmers who own agriculture assets probably receive higher quality service partly because they made more efforts in seeking useful services.

Farmers in villages with better infrastructure such as access to buses have reported higher services quality than farmers in villages without access to these infrastructures. However, farmers in richer villages appear to be slightly less happy with the changes in service quality than those in poorer villages although the magnitude of the effect is almost negligible. Farmers in richer villages may have a higher expectation and standard for the services they receive. Also, richer farmers probably access better extension services in the pre-period and hence any change would be smaller.

[INSERT Table 2 HERE]

The quality of extension services can also be reflected in the frequency of service uptakes, for example, farmers send queries to the Munnas and how promptly they are answered (Table A4, Appendix 2). We note a considerable increase in the uptake of services. As the baseline survey identified, more than 89 per cent of the member farmers made no queries to SCPCL. All of them, however, according to the final survey, had queries to get answered. Some farmers were even asking for information many times in a week reflecting farmers' increased/changed thirst for agricultural 
knowledge, practices and information. The technology also helped to deliver the services quickly. This indicates a massive improvement in the communication between farmers and SCPCL.

\subsection{The effect of ICT intervention on farmers' knowledge}

Table 3 reports results of the impact on agriculture knowledge. We use the pre- and postintervention changes in AKI as the dependent variable. We control for household characteristics and village level characteristics to minimise the sample selection bias. The RESET suggests that the model with village level factors is preferable to the model without them. ${ }^{5}$ The treatment effects model (Model 2) is preferable, but we also report OLS estimates (Model 1) for robustness checks.

\section{[INSERT Table 3 HERE]}

The estimated effect of KHETI on overall AKI tells us that, holding farmer- and villagespecific characteristics constant, given the mean AKI index of the treatment group before the intervention which was 0.62 , the eight months intervention led to an increase in farmers' access and knowledge by 14 per cent. The estimated coefficient of $N K$ is -0.058 and is significant at 5 per cent in the treatment model. This suggests that the change in agriculture knowledge in this group is lower than that in the control group. The Wald test indicates that the difference between the two estimated coefficients is significant at the 1 per cent level. We found that the knowledge level of this NK group at baseline was significantly higher than other members who were using $\mathrm{KHETI}^{6}$. So, given the higher knowledge level of this group at baseline, it is not surprising that knowledge increase of this group is less than the control group over the evaluation period.

Results of the OLS model are broadly consistent with the treatment effects model except that the estimated coefficient of the 'members did not use KHETI' variable is positive but insignificant. This is because the sample selection bias is not corrected in the OLS model. Nevertheless, the Wald test suggests that the difference between the two grouping dummies is still significant. This confirms 
that the technology designed in the KHETI was able to enhance knowledge and access in the project area.

Older farmers appear to have greater knowledge and awareness in agriculture techniques and information. The negative sign of the gender variable reflects the lower visibility of women in agriculture, which may be due to the social barrier in the Indian context. Women's engagement in agriculture is usually a hidden matter and it is difficult for them to get access to information before men. Interestingly, the estimated coefficient of the middle school education variable is not statistically significant. This is also true when education is measured using primary education ${ }^{7}$.

Farmers who have encroached land and rent-in land benefit more in terms of agriculture knowledge and awareness than those who have not. This again suggests that KHETI assisted those disadvantaged more than those relatively better off. Socio-economic status measured by caste categories does not appear to be significantly associated with the short-term changes in AKI. Farmers who have access to radio and television appear to have greater knowledge and awareness of agricultural knowledge, new practices and funding sources. The estimated coefficient of the village transportation infrastructure variable is positive and significant as expected. The estimated coefficients of the village economy variables suggest that farmers in richer villages reported less increase in AKI after the intervention, probably because of their better awareness and knowledge before the intervention. This reinforces our finding that KHETI helped the underprivileged more than those better off community.

The impact on type of knowledge is also reported in this Table 3 (Models 3 and 4). We focus on changes in general agriculture knowledge (Model 3) and their knowledge about agriculture practices and technology (Model 4). As the KHETI project provides bespoke agriculture practices in response to farmers' queries, we expect a greater increase in their agriculture practices and technology instead of general agriculture knowledge. So the resulting higher effect in Model 4 is consistent with 
our expectation. We did not include the changes in their access to funding into this exercise because this is a product of changes in both awareness and the actual availability of funding, which is beyond the scope of this research.

In Model 4, the significant coefficient of the $\mathrm{K}$ variable suggests that the changes in average knowledge in agriculture practices in the treatment group is 0.085 units higher than that in control group 1. While the coefficient of the NK variable is marginally significant at 10 per cent level, suggesting that the change in average knowledge in agriculture practices in control group 2 is 0.055 units lower than that in the control group 1. Taking these two pieces of evidence together, we can infer that the change in average knowledge in agriculture practices in the treatment group is 0.14 units higher than that in control group 2. The Wald test indicates that this difference is significant at 1 per cent.

Similarly, in Model 3, the change in general agriculture knowledge in the treatment group is 0.047 units higher than that in control group 1. The coefficient of the NK variable is marginally significant at 10 per cent level, indicating that the change in general agriculture knowledge in control group 2 is 0.054 units lower than that in the control group 1 . We can hence infer that the change in general agriculture knowledge in the treatment group is 0.10 units higher than that in control group 2. The Wald test statistic indicates that this difference is statistically significant. Comparing the results of Models 3 and 4, the impact of KHETI on the changes of knowledge of agriculture practices is higher than that on their general agriculture knowledge. This difference is 0.04 units, which is about twice the size of the changes in general agriculture knowledge.

Sample farmers were categorised based on their answer to the question of quality of Munna services - whether more useful or less/not useful. We have added Model 5 in Table 3 showing that the impact was higher on the farmers who rated the services most useful. 
With regard to the control variables, the general message is similar to that from Models 1 and 2 in Table 3. Farmers who were more backward in terms of land ownership and in poorer villages benefit more from the KHETI project. Women showed less increase in their knowledge than men. Households having radio and TV enjoyed a greater increase in knowledge of agriculture practice. Compare the results of Models 3 and 4: the effect of land ownership is significant in Model 4 but not 3. This is consistent with our finding that KHETI benefits those poorer communities more than the richer ones, and hence such effect appear more significantly in the focused areas of the KHETI intervention. The impact was higher on those gaining knowledge on farm practices and even higher on those who found the services most useful (model 5).

A further robustness check with comparable smaller samples is reported in Table 4. Seven different samples were identified with groupings matched with key identifiers such as land, income, mobile phone ownership and age. This sensitivity analysis shows that impacts are robust across samples.

\section{[INSERT Table 4 HERE]}

\subsection{Impact on farmers' aspiration}

The experience of using mobile phone technology assisted agricultural extension services may have also opened up the mind about modern technology and the changes in the external world and their relevance to their farming and life in general. We asked the farmers whether they think that the experience of using KHETI make them try more new technology for agricultural production" and whether they "think the experience of using KHETI make you [farmers] try more new technology and new ways of life in the future". About 99.4 per cent of the farmers replied "yes" to the first question and 99.1 per cent replied "yes" to the second question (Table 5). Although we recognise that there may be some psychological factors making the farmers more inclined to give a positive answer in the hope 
to continue to receive such free extension services, all this suggests the wider and deeper impact of the ICT-enhanced intervention on farmers' attitudes and aspiration for life and their future.

[Insert Table 5 here]

We also estimated the impact on access to credit, controlling for relevant variables (Table A5, appendix 2). About 21 per cent more of treatment farmers than control farmers had the likelihood of accessing credit. This means that 21 per cent more farmers would use credit if they are given access to services like KHETI.

\section{Conclusions}

This study examines the impact of an innovative video-enabled mobile phone technology on the speed and quality of agricultural services delivery. The usage of the services by small and marginal farmers improved their awareness and agricultural knowledge, as well as access to credit. This evaluation is based on an action research project, called KHETI, which provides speedy communication of audio-visual dialogues between farmers and agriculture experts. Local youths, called Munnas, carry mobile phone technology to connect farmers with agricultural experts. It aims to solve the problems of all selected farmers with timely and appropriate services. We employ pre- and post-intervention survey data collected through structured questionnaires.

Farmers assessed the quality of the services to be better than pre-intervention services. The experience of using the services has made farmers feel more at ease with new technology and adapting to new things for life in the future.

Admittedly, the longevity of farmers' attitude towards e-services is subject to continued examination. The poor farmers were unaware of KHETI before its invention. The experience, to a certain extent, opened farmers' minds regarding the relevance of modern ICTs to their production activities and their life. Of course, some evidence of changes in farmers' attitude is based on subjective 
indicators. We should be cautious about the possible exaggeration of impact due to social desirability bias, which is often not possible to control in social experiments. Additionally, evidence suggests that enhanced knowledge is linked to productivity/welfare gain. However, this is subject to the socioeconomic contexts/supportive system under which farmers work. Farmers may gain knowledge of practices and may have aspirations to improve their life using better practices, but if the required resources are not accessible then they will not be able to adopt new practices and apply their knowledge to improve productivity. However, given the currently increasing government and nongovernment initiatives to improve the accessibility of resources in remote areas in India, we would expect farmers better access to resources.

A crucial finding from this research is that the needy farmers gained more from this intervention than those who were better off. There may be some misconception that modern technologies benefit only the rich, but do not really work for the bottom of the pyramid. Evidence from the project suggests that mobile phone technology can generate significant developmental effects for the poor. This achievement of the project may be, to a certain extent, due to the choice of an appropriate technology, the mobile phone technology with Munna, instead of a more advanced networked internet system in the poorest part of India. This is a useful lesson that we can learn from the KHETI experience for future technology for development projects. Our evidence also suggests that the integration of audio and video technologies in the mobile phone and the mediation of trained village youth, Munna, enabled farmers with low levels of education or less land to gain from this mobile phone technology-assisted extension service. The impact was higher if services are more related to farm practices and technology and of better quality.

A fertile ground for future research would be to identify the improvement in various farm practices, efficiency and competitiveness due to mobile phone technology enhanced extension services and so direct the innovation towards supporting efficient and competitive farm practices by small and 
marginalised farmers. The technology was administered with support from a research funding body and cannot be sustained in its current form. However, given the current growth of cheaper smartphones, and the cost-effective employability of Munnas, KHETI can be adapted by the government to improve the efficacy of its extension services delivery. The state government could employ Munnas by saving money from engaging fewer specialist experts for effective extension services delivery. Partners can help develop longer term impact indicators of extension services to allow for assessment of sustainability and continued take-up of ICT-based interventions like the KHETI.

Current evidence of knowledge-aspirations-productivity linkages is still limited and, therefore, our results call for an increased attention of intervention-based studies examining such linkages.

${ }^{1}$ The non-member farmers were selected for interview such that they were not beyond the ranges of age, own land and per capita income of the members of SCPCL (a priori matching criteria). Selected 698 member farmers benefit from KHETI services and 507 non-member farmers receive no SCPCL services and unlikely to be benefitted from KHETI services.

${ }^{2}$ Strict randomness is in fact difficult to achieve in the field. Familiarity with the village of the interview team or convenience of interview in the field may often affect the random selection process.

${ }^{3}$ Although groups are similar with respect to important variables, we have found some differences. There may be two reasons: First, we do not have a baseline before the SCPCL intervention and so SCPCL without KHETI was already functioning when the baseline survey was conducted. We noted that AKI was higher for SCPCL members who did not adopt Munna services. This may be because a higher proportion of farmers $(21 \%)$ in this group used SCPCL services than other member group (only $6 \%$ of them used SCPCL services) before KHETI. Second, we expect some bias because some farmers self-select membership of SCPCL, although SCPCL intended to include all farmers/randomly selected farmers. This motivates us to carry out appropriate regression analysis (treatment effect and Tobit models).

${ }^{4} \mathrm{~F}_{3,1314}=0.26$, prob $>\mathrm{F}=0.86$ in the model with village level factors and $\mathrm{F}_{3,1317}=1.03$, prob $>\mathrm{F}=0.38$ in the model without village level factors, Breusch-Pagan $\mathrm{Chi}^{2}=33.66$, prob $>\mathrm{Chi}^{2}=0.00$.

${ }^{5}$ There is no significant error in model specification with village level factors $\left(\mathrm{F}_{3,1183}=2.53\right.$, prob $\left.>\mathrm{F}=0.06\right)$ but specification error is significant in the model without village level factors $\left(\mathrm{F}_{3,1187}=5.40\right.$, prob $\left.>\mathrm{F}=0.00\right)$.

${ }^{6}$ The average level of agriculture knowledge between the treatment and NK group is significant. The Knowledge and Awareness Index of control group 2 is 0.82 , about 0.19 units higher than that of the treatment group at 0.62 . This may partially explain why the farmers in NK group did not approach the Munnas for advice. ${ }^{7}$ Results using primary education as alternative measure of farmers' education background is not reported here due to space limit. They are available from the authors upon request. 


\section{References}

Aghion, P \& Howitt, P. (1992), “A Model of Growth through Creative Destruction”, Econometrica, 60, 323351.

Aker, J. C. (2011). "Dial "A" for Agriculture: A Review of Information and Communication Technologies for Agricultural Extension in Developing Countries," Agricultural Economics, 42(6): 631-647.

Anderson, J. R., \& Feder, G. (2004). “Agricultural Extension: Good Intentions and Hard Realities.” The World Bank Research Observer 19 (1): 41-60.

Bernard, T, Dercon, S, Orkin, K and Taffesse, A. (2014). 'The Future in Mind: Aspirations and ForwardLooking Behaviour in Rural Ethiopia'. London, Centre for Economic Policy Research.

Cameron, A. C. \& Trivedi, P. K. (2009). Microeconometrics Using Stata, Texas: A Stata Press Publication, Stata Corp LP.

Cole, S. A., \& Fernando, A. N. (2012). "The Value of Advice: Evidence from Mobile Phone-Based Agricultural Extension." Harvard Business School Working Paper No. 13-047.

Digital Green (2011). Digital Green Annual Report 2010-11, New Delhi, India.

Duflo, E., Glennerster, R. \& Kremer, M. (2008). "Using Randomization in Development Economics Research: A Toolkit," Handbook of Development Economics, Vol 4, Elsevier, chapter 61:3895-3914.

Erbaugh, J. M., Donnermeyer, J. \& Kibwika, P. (2001). "Evaluating Farmers' Knowledge and Awareness of Integrated Pest Management (IPM): Assessment of the IPM Collaborative Research Support Project in Uganda." Journal of International Agricultural and Extension Education, 8(1): 47-53.

Fafchamps, M. \& Minten, B. (2012). "Impact of SMS-based Agricultural Information on Indian Farmers”, The World Bank Economic Review, doi:10.1093/wber/lhr056.

Ferroni, M. \& Zhou, Y. (2012). "Achievements and Challenges in Agricultural Extension in India", Global Journal of Emerging Market Economies, 4(3): 319-346.

Foster, A.D., \& Rosenzweig, M. R. (1995). "Learning by Doing and Learning from Others: Human Capital and Technical Change in Agriculture", Journal of Political Economy 103(6):1176-1209. 
Godtland, E. M., Sadoulet, E., de Janvry, A., Murgai, R. \& Ortiz, O. (2004). "The impact of farmer field schools on knowledge and productivity: A study of potato farmers in the Peruvian Andes", Economic Development and Cultural Change, 53 (1):63-92.

Goyal, A. (2010). "Information, Direct Access to Farmers, and Rural Market Performance in Central India". American Economic Journal: Applied Economics, 2(3): 22-45.

Hayami, Y., \& Ruttan, V. W. (1970). Agricultural Productivity Differences among Countries. The American Economic Review, 60(5):895-911.

Heeks, R. \& Molla, A. (2009). "Compendium on Impact Assessment of ICT-for-Development Projects", IDRC-CERD.

ITU (2011). ITU STATSHOT, Issue 7, International Telecommunication Union, August.

Jack, K. (2011). "Market Inefficiences and the Adoption of Agricultural Technologies in Developing Countries," ATAI. 1, 3.

Jensen, R. (2007). "The Digital Provide: Information (Technology) Market Performance, and Welfare in the South Indian Fisheries Sector", The Quarterly Journal of Economics, 122(3): 879-924.

Kijima, Y., Ito, Y. \& Otsuka, K. (2012). "Assessing the Impact of Training on Lowland Rice Productivity in an African Setting: Evidence from Uganda", World Development, 40(8): 1610-1618.

Lee, K. H. \& Bellemare, M. F. (2013). Look Who's Talking: The Impact of Intrahousehold Allocation of Mobile Phones on Agricultural Prices, the Journal of Development Studies, 49(5): 624-640.

Mehta, B. S. (2013). Capabilities, Costs, Networks and Innovations: Impact of Mobile Phones in Rural India, Working Paper 29, Institute of Human Development, New Delhi, India.

Meera S. N, Jhamtani, A. \& Rao D. U M. (2004). Information And Communication Technology In Agricultural Development: A Comparative Analysis Of Three Projects From India, Network Paper no. 135, Overseas Development Institute, London.

Ogutu, S. O., Okello, J. J. \& Otieno, D. J. (2014). "Impact of Information and Communication TechnologyBased Market Information Services on Smallholder Farm Input Use and Productivity: The Case of Kenya", World Development. 64: 311-321. 
Phillips, J. M. (1994). "Farmer Education and Farmer Efficiency: A Meta-Analysis", Economic Development and Cultural Change, 43(1):149-65.

Raabe, K. (2008). "Reforming the agricultural extension system in India: What do we know about what works where and why?," IFPRI discussion paper 775, International Food Policy Research Institute, Washington D.C.

Ravallion, M. (2008). "Evaluating Anti-Poverty Programs" in T. Paul Schultz \& John A. Strauss (ed.), Handbook of Development Economics, Elsevier, edition 1, 4(5), chapter 59: 3787-3846.

Reimers, M. \& Klasen, S. (2013). "Revisiting the Role of Education for Agricultural Productivity", American Journal of Agricultural Economics, 95(1):131-152.

Rizvi, S. M. H. \& Dearden, A. (2010). Knowledge Help Extension Technology Initiative (KHETI) - A Participatory Interactive ICT Designed Solution in Agriculture for Livelihoods Promotions, accessed at http://www.iimahd.ernet.in/egov/ifip/oct2010/syed-rizvi.htm

Romer, P. M. (1990). "Endogenous Technological Change", Journal of Political Economy, 98(5) Part 2:S71S102.

Rubin, D. B. (1974). "Estimating Causal Effects of Treatments in Randomized and Nonrandomized Studies." Journal of Educational Psychology, 66(5): 688-701.

Sen, A. (1989). “Development as Capability Expansion,” Journal of Development Planning 19: 41-58.

Smith, R. B. W., Gemma, M. \& Palinisami, K. (2011). "Profit based Efficiency Measures, with an Application to Rice Production in Southern India", Journal of Agricultural Economics, 62(2): 340356.

Solow, R. (1957). "Technical Change and the Aggregate Production Function", Review of Economics and Statistics, 39: 312-320.

United Nations, (2005). “Global E-government Readiness Report: From E-Government to E-Inclusion”, UNPAN/2005/14, United Nations, New York.

van den Berg, H. \& Jiggins, J. (2007). "Investing in Farmers - The Impacts of Farmer Field Schools in Relation to Integrated Pest Management.” World Development. 35(4): 663-686. 
World Bank, (2012). “Information and Communications for Development 2012: Maximizing Mobile”, World Bank, Washington DC.

Zanello, G; Srinivasan, C. S. \& Shankar, V. (2014). "Transaction Costs, Information Technologies, and the Choice of Marketplace among Farmers in Northern Ghana", the Journal of Development Studies, 50(9): 1226-1239. 
Table 1. Baseline pre-treatment characteristics of the treatment and the control groups

\begin{tabular}{|c|c|c|c|c|c|c|c|}
\hline & Control & Treatment & & Of which & & & Total \\
\hline & $\begin{array}{c}\text { non- } \\
\text { SCPCL }\end{array}$ & $\begin{array}{l}\text { SCPCL } \\
\text { member }\end{array}$ & t-test & $\begin{array}{c}\text { SCPCL } \\
\text { No } \\
\text { Munna }\end{array}$ & $\begin{array}{l}\text { SCPCL } \\
\text { With } \\
\text { Munna }\end{array}$ & t-test & \\
\hline & (C) & $(\mathrm{T})$ & & $(1)$ & $(2)$ & & $(\mathrm{C}+1+2)$ \\
\hline \multicolumn{8}{|l|}{ Income \& assets } \\
\hline has tractor & 0.01 & 0.02 & \multirow{8}{*}{$*$} & 0.03 & 0.02 & & 0.02 \\
\hline has thresher & 0.00 & 0.01 & & 0.01 & 0.01 & & 0.01 \\
\hline has fertiliser/seed drill & 0.01 & 0.01 & & 0.02 & 0.01 & & 0.01 \\
\hline has plough & 0.00 & 0.01 & & 0.01 & 0.01 & & 0.00 \\
\hline has Mobile & 0.06 & 0.13 & & 0.11 & 0.14 & & 0.10 \\
\hline has radio/TV & 0.06 & 0.08 & & 0.04 & 0.08 & & 0.06 \\
\hline Access to loan (Rs) & 14477 & 12155 & & 16032 & 12155 & & 13529 \\
\hline Family income (Rs) & 11055 & 13338 & & 14379 & 12888 & & 12375 \\
\hline \multicolumn{8}{|l|}{ Land } \\
\hline Own land (acres) & 3.17 & 3.03 & & 3.07 & 3.02 & & 3.09 \\
\hline \multicolumn{8}{|l|}{ Education } \\
\hline Illiteracy & 0.52 & 0.48 & & 0.52 & 0.47 & & 0.50 \\
\hline \multicolumn{8}{|l|}{ Training } \\
\hline ICT or any other & 0.00 & 0.00 & & 0.00 & 0.00 & & 0.00 \\
\hline \multicolumn{8}{|l|}{ Social } \\
\hline Age & 39.35 & 38.42 & \multirow{6}{*}{$*$} & 39.01 & 38.17 & & 38.81 \\
\hline Female & 0.03 & 0.18 & & 0.15 & 0.20 & & 0.12 \\
\hline Other backward caste & 0.54 & 0.52 & & 0.49 & 0.54 & & 0.53 \\
\hline No of children & 2.56 & 2.41 & & 2.45 & 2.40 & & 2.48 \\
\hline No of adults & 2.15 & 2.35 & & 2.43 & 2.31 & & 2.26 \\
\hline Primary occupation is agri. & 0.99 & 1.00 & & 1.00 & 0.99 & & 0.99 \\
\hline \multicolumn{8}{|l|}{ Village environment } \\
\hline Bus from village & 0.54 & 0.51 & & 0.47 & 0.53 & & 0.52 \\
\hline Electricity in village & 0.61 & 0.70 & $*$ & 0.53 & 0.77 & $*$ & 0.66 \\
\hline$N$ & 507 & 698 & & 206 & 492 & & 1205 \\
\hline
\end{tabular}

Note: * indicates t-test of equal means between the groups to be significant at 5 per cent level.

Source: Questionnaire survey 2008.

Rs. is Indian currency Rupees (1 US\$= Rs 48.8 during the survey in November 2008). 
Table 2. Regression results: impact of ICT on quality of extension services

\begin{tabular}{|c|c|c|c|c|c|c|c|c|}
\hline & \multicolumn{2}{|c|}{ OLS Model 1} & \multicolumn{2}{|c|}{ OLS Model 2} & \multicolumn{2}{|c|}{ Tobit Model 1} & \multicolumn{2}{|c|}{ Tobit Model 2} \\
\hline & Coef. & $\mathrm{SE}$ & Coef. & SE & Coef. & SE & Coef. & SE \\
\hline Adopted KHETI (K) & $0.359 * * *$ & 0.014 & $0.360 * * *$ & 0.005 & $0.435 * * *$ & 0.025 & $0.435 * * *$ & 0.024 \\
\hline Not adopted KHETI (NK) & $0.330 * * *$ & 0.008 & $0.330 * * *$ & 0.005 & $0.379 * * *$ & 0.012 & $0.380 * * *$ & 0.013 \\
\hline Age & $0.001 * * *$ & 0.000 & $0.001 * * *$ & 0.000 & $0.001 * * *$ & 0.000 & $0.001 * * *$ & 0.000 \\
\hline Area rented in & -0.001 & 0.001 & -0.001 & 0.001 & -0.002 & 0.001 & -0.002 & 0.002 \\
\hline Area rented out & $-0.006^{*}$ & 0.004 & -0.006 & 0.004 & $-0.008^{*}$ & 0.005 & $-0.008^{*}$ & 0.005 \\
\hline Tropical livestock unit & -0.002 & 0.002 & -0.003 & 0.002 & -0.003 & 0.003 & -0.003 & 0.003 \\
\hline Farmer's gender & -0.001 & 0.009 & 0.001 & 0.009 & -0.005 & 0.013 & -0.004 & 0.013 \\
\hline Middle school education & 0.000 & 0.009 & 0.006 & 0.009 & -0.004 & 0.014 & 0.002 & 0.013 \\
\hline Primary education & 0.007 & 0.007 & 0.007 & 0.007 & 0.012 & 0.010 & 0.010 & 0.009 \\
\hline Backward caste & -0.014 & 0.014 & -0.017 & 0.010 & -0.014 & 0.022 & -0.022 & 0.016 \\
\hline Schedule caste or tribe & -0.009 & 0.010 & -0.007 & 0.008 & -0.010 & 0.016 & -0.012 & 0.011 \\
\hline Access to credit & 0.007 & 0.006 & 0.010 & 0.007 & 0.007 & 0.008 & 0.012 & 0.010 \\
\hline Marital state & 0.018 & 0.014 & 0.021 & 0.014 & 0.025 & 0.018 & 0.027 & 0.019 \\
\hline Irrigation facilities & $-0.037 * * *$ & 0.010 & $-0.038^{* * *}$ & 0.009 & $-0.044 * * *$ & 0.012 & $-0.047 * * *$ & 0.011 \\
\hline Agricultural assets & $0.014^{* *}$ & 0.006 & $0.012 * * *$ & 0.005 & $0.019^{* *}$ & 0.009 & $0.017 * * *$ & 0.007 \\
\hline Village has buses & & & $0.019^{*}$ & 0.010 & & & $0.027^{*}$ & 0.015 \\
\hline Village has electricity & & & 0.005 & 0.018 & & & 0.010 & 0.025 \\
\hline Village economy envir. & & & $-0.001 * *$ & 0.000 & & & $-0.001 * *$ & 0.000 \\
\hline Constant & $0.541 * * *$ & 0.014 & $0.532 * * *$ & 0.022 & $0.523 * * *$ & 0.021 & $0.518 * * *$ & 0.028 \\
\hline $\mathrm{N}$ & 1336 & & 1336 & & 1336 & & 1336 & \\
\hline OLS R²/Tobit sigma & 0.76 & & 0.77 & & $0.134 * * *$ & 0.006 & $0.133^{* * *}$ & 0.006 \\
\hline Log pseudolikelihood & & & & & 236.26 & & 243.45 & \\
\hline Wald test $\left(\mathrm{H} 0: \vartheta_{1}=\vartheta_{2}\right)$ & $6.25 * *$ & & $5.76^{* *}$ & & $6.50^{* * *}$ & & $6.44 * * *$ & \\
\hline
\end{tabular}

Notes: Dependent variable is quality index. ${ }^{* * *} \mathrm{p}<0.01,{ }^{* *} \mathrm{p}<0.05,{ }^{*} \mathrm{p}<0.1$. White's heteroskedasticity-corrected robust standard errors are clustered at village level.

Sample: the treatment group before and after the intervention.

$\mathrm{H} 0$ of the Wald test: the estimated coefficient of ' $\mathrm{K}$ ' variable equals that of 'NK' variable. 
Table 3. Impact of ICT on changes in farmers' knowledge and awareness

\begin{tabular}{|c|c|c|c|c|c|}
\hline & \multirow[b]{2}{*}{ Model 1 OLS } & \multirow[b]{2}{*}{ Model 2 Treatment effects } & \multirow[b]{2}{*}{$\begin{array}{c}\text { Model } 3 \text { Treatment effects } \\
\text { Agri knowledge }\end{array}$} & \multirow[b]{2}{*}{$\begin{array}{c}\text { Model } 4 \text { Treatment } \\
\text { effects Agri practices \& } \\
\text { tech }\end{array}$} & \multirow[b]{2}{*}{$\begin{array}{l}\text { Model } 5 \text { Treatment } \\
\text { effects Farmers said } \\
\text { services most useful } \\
\end{array}$} \\
\hline & & & & & \\
\hline Adopted KHETI (K) & $0.091 * *(0.045)$ & $0.089 * * *(0.008)$ & $0.047 * * *(0.009)$ & $0.085^{* * *}(0.010)$ & $0.157 * * *(0.024)$ \\
\hline Age & $0.001 *(0.000)$ & $0.001 * *(0.000)$ & $0.001 *(0.000)$ & $0.001 *(0.000)$ & $0.001^{* *}(0.000)$ \\
\hline Number of persons in agr. & $-0.002(0.003)$ & $0.003(0.004)$ & $0.004(0.004)$ & $0.004(0.004)$ & $0.005(0.004)$ \\
\hline Area owned & $-0.001(0.001)$ & $-0.001(0.001)$ & $-0.001(0.001)$ & $-0.002 *(0.001)$ & $-0.002(0.001)$ \\
\hline Area encroached & $0.007(0.005)$ & $0.007 * * *(0.002)$ & $0.003(0.002)$ & $0.007 * * *(0.003)$ & $0.019 * * *(0.003)$ \\
\hline Area rented in & $0.001(0.001)$ & $0.005 * *(0.002)$ & $0.003(0.002)$ & $0.006^{* *}(0.002)$ & $0.006^{* * *}(0.002)$ \\
\hline Area rented out & $-0.002(0.005)$ & $-0.001(0.005)$ & $0.001(0.006)$ & $0.001(0.006)$ & $0.003(0.006)$ \\
\hline Farmer's gender & $-0.060 *(0.032)$ & $-0.058 * * *(0.012)$ & $-0.046 * * *(0.012)$ & $-0.064 * * *(0.013)$ & $-0.081 * * *(0.013)$ \\
\hline Middle school education & $0.001(0.011)$ & $0.004(0.014)$ & $0.014(0.014)$ & $0.004(0.015)$ & $0.011(0.018)$ \\
\hline Schedule caste or tribe & $0.006(0.013)$ & $0.010(0.013)$ & $0.002(0.014)$ & $0.007(0.015)$ & $0.053 * * *(0.016)$ \\
\hline Access to credit & $-0.012(0.028)$ & $-0.005(0.008)$ & $0.015^{*}(0.009)$ & $-0.004(0.009)$ & $-0.014(0.010)$ \\
\hline Has radio/TV $=1$ & $0.033(0.026)$ & $0.026 *(0.015)$ & $0.026 *(0.016)$ & $0.038^{* *}(0.017)$ & $0.040^{* *}(0.018)$ \\
\hline Village has bus & $0.034(0.028)$ & $0.038 * * *(0.009)$ & $0.023 * * *(0.009)$ & $0.033 * * *(0.010)$ & $0.016(0.011)$ \\
\hline Village economy & $-0.001 *(0.001)$ & $-0.001 * * *(0.000)$ & $-0.001 * *(0.000)$ & $-0.001 * * *(0.000)$ & $-0.003 * * *(0.000)$ \\
\hline Village average income & $-0.003(0.002)$ & $-0.003 * * *(0.000)$ & $-0.003 * * *(0.000)$ & $-0.002 * * *(0.001)$ & $-0.004 * * *(0.001)$ \\
\hline Constant & $0.024(0.032)$ & $0.015(0.020)$ & $-0.006(0.021)$ & $0.011(0.022)$ & $0.018(0.028)$ \\
\hline $\mathrm{N}$ & 1191 & 1191 & 1191 & 1191 & 1081 \\
\hline $\mathrm{R}^{2} /$ Wald Chi2 & 0.152 & $381.81 * * *$ & $249.58 * * *$ & $324.06 * * *$ & $407.65 * * *$ \\
\hline Wald test $\left(\mathrm{H} 0: \gamma_{1}=\gamma_{2}\right)$ & $2.78^{*}$ & $28.97 * * *$ & $12.47 * * *$ & $20.96 * * *$ & $26.94 * * *$ \\
\hline Lamda & 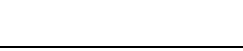 & $0.051 * * *$ & $0.041 * * *$ & $0.054 * * *$ & $0.093 * * *$ \\
\hline
\end{tabular}

Notes: $* * * \mathrm{p}<0.01,{ }^{* *} \mathrm{p}<0.05,{ }^{*} \mathrm{p}<0.1$. Figures in brackets are standard errors. Heteroskedasticity corrected robust and village clustering adjusted standard errors are reported for Model 1. Treatment-effects estimates are presented in Models 2-4. Dependent variable: difference in awareness-knowledge index before and after KHETI intervention. Wald tests rejected the null hypothesis that the estimated coefficient of K equals to that of NK variable. Models 3 and 4 are components of knowledge index. 
Table 4. Impact of ICT on changes in farmers' knowledge and awareness (further robustness check with matching groups)

\begin{tabular}{|c|c|c|c|c|}
\hline & \multicolumn{2}{|c|}{$\begin{array}{c}\text { Model } 1 \\
\text { OLS with village } \\
\text { clustering adj. SE }\end{array}$} & \multicolumn{2}{|c|}{$\begin{array}{c}\text { Model } 2 \\
\text { Treatment effects } \\
\text { model }\end{array}$} \\
\hline & Coef. & $\mathrm{SE}$ & Coef. & SE \\
\hline \multicolumn{5}{|l|}{ 1. Matched with own land $(\mathrm{N}=1135)$} \\
\hline Adopted $K H E T I(K)$ & $0.093 * *$ & 0.046 & $0.092 * * *$ & 0.009 \\
\hline Members not adopted KHETI (NK) & 0.023 & 0.021 & $-0.058 * *$ & 0.029 \\
\hline \multicolumn{5}{|l|}{ 2. Matched with own land $(\mathrm{N}=960)$} \\
\hline Adopted KHETI $(K)$ & $0.103 * *$ & 0.05 & $0.089 * * *$ & 0.008 \\
\hline Members not adopted KHETI (NK) & 0.023 & 0.022 & $-0.057 *$ & 0.032 \\
\hline \multicolumn{5}{|l|}{ 3. Matched with income $(\mathrm{N}=1041)$} \\
\hline Adopted KHETI $(K)$ & $0.098 * *$ & 0.048 & $0.095 * * *$ & 0.009 \\
\hline Members not adopted KHETI (NK) & 0.023 & 0.022 & $-0.069 * *$ & 0.029 \\
\hline \multicolumn{5}{|l|}{ 4. Matched with income $(\mathrm{N}=1054)$} \\
\hline Adopted KHETI $(K)$ & $0.083 * *$ & 0.043 & $0.082 * * *$ & 0.009 \\
\hline Members not adopted KHETI (NK) & 0.023 & 0.021 & $-0.047 * *$ & 0.026 \\
\hline \multicolumn{5}{|l|}{ 5. None has mobile phone $(\mathrm{N}=1076)$} \\
\hline Adopted $\operatorname{KHETI}(K)$ & $0.100^{* *}$ & 0.048 & $0.099 * * *$ & 0.009 \\
\hline Members not adopted KHETI (NK) & 0.028 & 0.022 & $-0.045 * *$ & 0.027 \\
\hline \multicolumn{5}{|l|}{ 6. Matched with age $(\mathrm{N}=652)$} \\
\hline Adopted KHETI $(K)$ & $0.092^{* *}$ & 0.044 & $0.089 * * *$ & 0.011 \\
\hline Members not adopted KHETI (NK) & 0.018 & 0.017 & $-0.047 * *$ & 0.036 \\
\hline \multicolumn{5}{|l|}{ 7. Matched with age $(\mathrm{N}=777)$} \\
\hline Adopted KHETI $(K)$ & $0.096^{* *}$ & 0.048 & $0.094 * * *$ & 0.009 \\
\hline Members not adopted KHETI (NK) & 0.024 & 0.024 & -0.048 & 0.036 \\
\hline
\end{tabular}


Table 5. The impact of KHETI project on farmers' attitude and aspiration

\begin{tabular}{lccc}
\hline & & Freq. & Per cent \\
\hline $\begin{array}{l}\text { Do you think the experience of using KHETI } \\
\text { made you try more new technology for }\end{array}$ & No & 4 & 0.6 \\
agricultural production? & Total & 693 & 99.4 \\
& & 698 & 100.0 \\
Do you think the experience of using KHETI & No & 6 & 0.9 \\
made you try more new technology \& new & Yes & 691 & 99.1 \\
ways of life in the future? & Total & 698 & 100.0 \\
\hline
\end{tabular}

Source: The 2009 evaluation survey. 


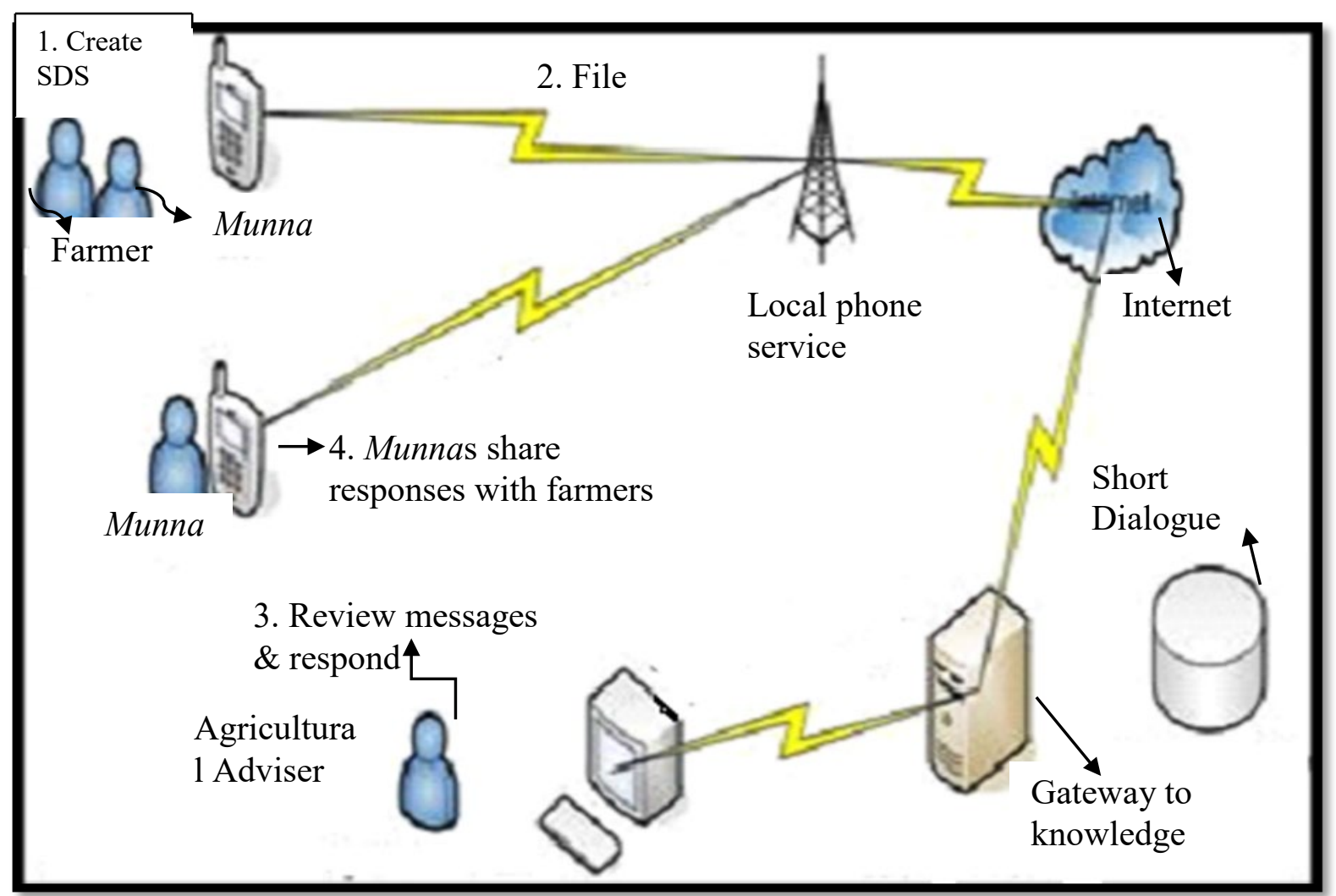

Source: KHETI Project data Base

Figure 1. Using Short Dialogue Strips to seek advice from Agriculture Adviser 


\section{Appendix 1. \\ The KHETI project}

KHETI was the outcome of the Rural E-Services project in India (ReSPI) funded by the Engineering and Physical Sciences Research Council, United Kingdom. This action research project was implemented by several UK organisations including the University of Oxford, and Indian partners. The project was piloted with the Sironj Crop Producers Company Private Limited (SCPCL) - a cooperative-type NGO formed by small and marginalised farmers from the villages around Sironj block, a sub-district of the Vidisha district of the State of Madhya Pradesh in India (Rizvi \& Dearden, 2010; Dearden, Mathews \& Rizvi, 2011). The block comprises 225 poorly connected villages. Most of the people in these villages are farmers. The villages are small ranging from around 10 to 100 farming households. KHETI provides farmers with bespoke individual advice to SCPCL members, since farmers' demand for advice/information is variable and is related to their current problems for which they need immediate solutions.

\section{Who were the members of SCPCL?}

SCPCL had 698 members, who are small and marginal farmers. Farmer selection criteria were land, other income sources and village infrastructure like the villages in the Sironj block. SCPCL intended to include all farmers/randomly selected farmers from randomly selected villages in the Sironj block. Thirty villages were initially included. However, some farmers self-selected not to be involved with SCPCL.

A survey of 1205 farmers including 698 SCPCL members in 2008 shows variations in land holding, with an average of around 3 acres and a median of 2 acres. Ten per cent of the 1205 owned mobile phones ( $15 \%$ for SCPCL members). Of the mobile phone holders, 70 per cent reported that they used their phone "rarely". In comparison, 6 per cent reported having a TV and 2 per cent having a radio while 66 per cent of the farmers reported that they had electricity in their villages.

\section{SCPCL activities}

Prior to KHETI, SCPCL had a specialist agricultural adviser. SCPCL paid him from its own funding along with supports from the state government. The activities were of two types: 
1. Provide advice and support to farmers: Examples of advice include: how to treat a particular pest, the best irrigation schedule for a crop, fertiliser doses and so forth. SCPCL also provided farmers with price information for inputs and outputs. Farmers bought seeds, fertiliser and pesticides from SCPCL at prices lower than the Sironj market. SCPCL's agriculture adviser was based in its office at Sironj city. The office was equipped with a land telephone, computer and the internet.

2. Generate operating revenue: SCPCL bought members' agricultural products (for example, Soya, wheat, gram) at a price slightly higher than Sironj grain market price and sold to processors at higher prices. SCPCL also administered a seed breeding programme to develop high-yielding varieties that are well adapted to local conditions.

Realistically it was impossible for SCPL to satisfy the needs of all farmers with one agriculture adviser due to the involvement of huge travel time, costs, poor road conditions and limited capacity. Farmers' travelling in the peak seasons affects farming activities negatively. Therefore, there is a strong need for a system like KHETI to enhance the flow of timely information at farmers' door-step.

\section{KHETI intervention: rationale and description}

The primary objective of KHETI was to speed up the communications between the farmers and agriculture experts. KHETI was designed through participatory exercises (interviews, FGDs and other methods, see details in Rizvi \& Dearden, 2010). A matrix of farmers' needs was developed and an Agricultural Information Flow System was identified as the 'area' where a solution could be designed.

The developed features and their functionalities aim to improve communications amongst various stakeholders especially between SCPCL farmers, the SCPCL Agriculture Specialist Adviser, community farmer representatives, SCPCL staffs/administration/advisers.

The KHETI system has three components:

First, the KHETI system was designed on a mobile phone platform. Smartphones with multi-media functions were used to create Short Dialogue Strips (SDSs). SDSs are audio-visual creations on the local agriculture problem, issues and knowledge. An SDS includes a maximum of six images and two minutes of audio recording. The system used camera phones (Nokia N73). They were more advanced than the mobile 
phones used in rural India. Only 10 per cent of the 1205 farmers interviewed had mobile phones but none of them had a smartphone.

Second, farmers and agriculture experts need to be connected. So the system used a mechanism for recording and logging telephone conversations between farmers and experts. This was achieved by having a server attached to two telephone lines.

Third, farmers could not make SDSs by themselves. The farmers demanded a person in their villages, called Munna, to assist them in making SDSs on their problems and facilitate their communication with agriculture adviser. The project recruited the Munnas from the village where he/she could easily facilitate the communication between an agricultural scientist and farmers. The Munnas sent the audio visual records to a web server, which could be accessed by the agricultural adviser in his office in the city. The adviser was then able to respond either by creating other SDSs or by phoning the Munnas/farmer. In this interactive system, specialists and farmers did not need to physically visit each other.

The central role in KHETI is Munna, who held the camera phone. Each Munna was responsible for 45 close vicinity villages within a $5 \mathrm{~km}$ radius of their home and was expected to visit each village at least once per week (previously, the adviser would reach each village at most once per month). So, the farmers are able to contact a Munna immediately if a problem arises or information is necessary. Munnas' own villages were served by different Munnas in an effort to avoid perceptions of inequality of service.

Munnas were paid a small part-time stipend, calculated with reference to the legal minimum wage. As the project evolved, the pattern adopted was that a Munna would visit two villages in one afternoon to meet with farmers and discuss issues. Munnas carried the smartphones and helped farmers and agriculture experts to exchange queries and solutions through SDSs. They were all trained by the project for capacity building before going to the field.

The farmers received the services without charge, although there was an intention to charge a minimum fee in the future to cover Munnas' labour costs and make the project sustainable.

\section{KHETI activities}


KHETI services include issues related to insect attacks on crops; diseases in soybean, gram, wheat and vegetables; choices of crops in case of unavailability or reduced availability of water; choices of crops against the soil type and patterns of crop rotation; premature fruits and flowering; quantity and type of fertiliser to use; choices of seeds; effects of termites on soil and the treatment. SCPCL was trying to provide all these services to farmers before KHETI but unable to do so without this innovative solution. Over three months of trial beginning August 2008, around 200 SDS were uploaded. A sample of 98 SDSs was translated into English for analysis.

Of the 98 SDSs, issues accounted 28 per cent for the major crop soya, followed by 10 per cent for chilli, followed by 7 per cent for tomato, and the remaining SDSs were issues with other crops and various other agriculture related concerns (Rizvi \& Dearden, 2010; Dearden et al., 2011). The queries were regarding pests $(30 \%)$, poor development of a crop $(41 \%)$, or explicit suggestions and about diseases $(6 \%)$. The major pests were insects including green mosquitoes or insect larvae. The images were useful to identify the pest to suggest accurate treatments. Other queries in the project period were falling of leaves, vegetable flowers were not producing fruits, termites on soil, and choice of crop rotation. SCPCL also continued its previous operations of supplying price information and trading activities.

Farmers could use their own phone to access the toll-free number of the adviser, but it was less effective than KHETI, because of two major reasons. First, only a small proportion of SCPCL farmers had access to mobile phones. Second, farmers themselves found it difficult to explain problems in their field. So Munnas and images were the solutions. Munnas were given specific training for making and uploading/transferring good quality SDSs, some general training so that they could provide advice on certain issues without asking the adviser, and some communication training (by a communication specialist) including building of social relationships.

From SDSs and phone conversation with Munnas and farmers, the adviser was clear about the problem. Over 80 per cent of members trusted SCPCL more than their local council (Panchayat), block, district or state government. Munnas built their own awareness of relevant knowledge and performed as actors in a network that helped the community to meet their regular challenges. The project supported the 
SCPCL staff including training of the Munnas. A local partner researcher worked closely with SCPCL and Munnas and monitored progress. In our survey, we included questions on how farmers consider quality of the services in terms of solving their queries effectively.

\section{Sustainability issues}

The project paid for the equipment and software, the costs of mobile services, the office broadband service and the Munnas. The salary of the Agricultural Communication Specialist (ACS) and office electricity bills were paid by PRADAN. The adviser was paid from SCPCL trading surpluses and subsidies from the state government. It altogether cost approximately Rs. 80 per query, which the poor farmers cannot afford to pay. Each Munna was handling 15 messages per month, which was much lower than the estimated 123 messages per month (at 123 messages cost per query is estimated to be Rs. 10). The capacity of ACS and Munna was not fully used. They could be part time and if efficient then costs could be made lower at Rs. 10 per query. Given the current growth of cheaper smartphone and the possibility that Munnas can be employed in a cost-effective way, the technology can be adapted by the government to improve the efficacy of its extension services delivery. The state government could seek private sector partner and employ agriculture assistants like the Munna by saving money from employing a fewer number of specialist agriculture experts for effective extension services delivery.

\section{Reference:}

Dearden, A., Mathews, P. \& Rizvi, H. (2011). Kheti: Mobile multimedia in an Agricultural Co-operative. Personal and Ubiquitous Computing, 15(6): 597-607. 


\section{Appendix 2}

Table A1. Questions related to component attributes of knowledge, awareness and quality of extension services and methodology of constructing indices.

\begin{tabular}{|c|c|c|c|c|}
\hline & $\begin{array}{l}\text { Minimum } \\
\text { score }\end{array}$ & $\begin{array}{l}\text { Maximum } \\
\text { score }\end{array}$ & $\begin{array}{l}\text { Indices } \\
\text { Minimum }\end{array}$ & $\begin{array}{l}\text { Indices } \\
\text { Maximum }\end{array}$ \\
\hline \multicolumn{5}{|l|}{$\begin{array}{l}\text { Questions asked to the farmers: Do you feel which } \\
\text { of the lack of the following a big constraint for you } \\
\text { (rank from } 0 \text { to } 5 \text { low to high)? }\end{array}$} \\
\hline Agriculture knowledge & 0 & 5 & $(0 / 5)=0$ & $(5 / 5)=1$ \\
\hline New agriculture practices / technology & 0 & 5 & $(0 / 5)=0$ & $(5 / 5)=1$ \\
\hline Funding to use this knowledge & 0 & 5 & $(0 / 5)=0$ & $(5 / 5)=1$ \\
\hline Funding even for basic agri services & 0 & 5 & $(0 / 5)=0$ & $(5 / 5)=1$ \\
\hline Awareness-knowledge index (AKI) & 0 & 20 & $(0 / 20)=0$ & $(20 / 20)=1$ \\
\hline \multicolumn{5}{|l|}{$\begin{array}{l}\text { Questions asked to the farmers: From your } \\
\text { experience, how useful is the advice from different } \\
\text { sources of agricultural information / advice? } \\
\text { [1=very bad quality, } 2=\text { bad, } 3=\text { acceptable, } 4=\text { good, } \\
5=\text { =very good }]^{*}\end{array}$} \\
\hline Munnas/SCPCL & 1 & 5 & $(1 / 5)=0.2$ & $(5 / 5)=1$ \\
\hline Other NGOs & 1 & 5 & $(1 / 5)=0.2$ & $(5 / 5)=1$ \\
\hline Other farmers & 1 & 5 & $(1 / 5)=0.2$ & $(5 / 5)=1$ \\
\hline Government extension services & 1 & 5 & $(1 / 5)=0.2$ & $(5 / 5)=1$ \\
\hline Household members & 1 & 5 & $(1 / 5)=0.2$ & $(5 / 5)=1$ \\
\hline Radio & 1 & 5 & $(1 / 5)=0.2$ & $(5 / 5)=1$ \\
\hline TV & 1 & 5 & $(1 / 5)=0.2$ & $(5 / 5)=1$ \\
\hline Newspaper & 1 & 5 & $(1 / 5)=0.2$ & $(5 / 5)=1$ \\
\hline Any other & 1 & 5 & $(1 / 5)=0.2$ & $(5 / 5)=1$ \\
\hline Quality index QI for Munnas & 1 & 5 & $(1 / 5)=0.2$ & $(5 / 5)=1$ \\
\hline Quality index (QI) for other sources & 8 & 40 & $(8 / 40)=0.2$ & $(40 / 40)=1$ \\
\hline
\end{tabular}

*There were eight sources other than Munnas. Farmers knew these other sources before the intervention. The government services appeared the worst and the Munnas were the best in terms of quality. As for an individual source, the scores ranged from 1 to 5, the Likert-type scale. The sum of the scores from 8 sources before the intervention ranged from 8 to 40 . We standardised the scores of both before and after situations into positive numbers up to a maximum of 1 . 
Table A2. Description of variables

\begin{tabular}{|l|c|c|}
\hline Variables & Mean & St Dev \\
\hline Farmers adopted KHETI services (K) & 0.408 & 0.492 \\
\hline Farmers not adopted KHETI services (NK) & 0.171 & 0.377 \\
\hline Awareness index (AKI) & 0.681 & 0.180 \\
\hline Number of persons in household in agriculture & 2.253 & 1.042 \\
\hline Area in acres owned by the farm household (ownland) & 3.090 & 3.362 \\
\hline Area in acre encroached by the household & 0.431 & 1.544 \\
\hline Area in acres rented in by the household (Rentin) & 0.310 & 1.973 \\
\hline Area in acres rented out by the household (Rentout) & 0.091 & 0.696 \\
\hline Farmer's gender (female=1) (gender_1) & 0.120 & 0.325 \\
\hline Farmer has middle school education=1 (edu_4) & 0.082 & 0.275 \\
\hline Farmer has primary school education=1 (edu_5) & 0.377 & 0.485 \\
\hline Backward caste=1 (caste_2) & 0.529 & 0.499 \\
\hline Schedule caste or tribe=1 (scst) & 0.360 & 0.480 \\
\hline Farmer has access to credit=1 (credit) & 0.552 & 0.498 \\
\hline Farmer has radio/TV=1 (rdtv) & 0.069 & 0.253 \\
\hline Village has access to bus=1 (BusV) & 0.721 & 0.449 \\
\hline Village has access to electricity=1 (ElectV) & 0.841 & 0.366 \\
\hline Village average income (Rs) & 15125 & 8640 \\
\hline $\begin{array}{l}\text { Village economy measured by the total number of sample farmers in } \\
\text { the village have access to electricity, mobile phone and TV } \\
\text { (villecoprop) }\end{array}$ & 26.47 & 20.74 \\
\hline Age of farmer (years) (Age) & & \\
\hline Tropical livestock unit (Tlu) & 38.812 & 12.641 \\
\hline Marital status, married=1 (mstat_2) & 1.195 & 1.294 \\
\hline Farmers have irrigation facilities=1 (irfac_2) & 0.942 & 0.234 \\
\hline Farmers have agricultural assets=1 (Agas) & 0.191 & 0.393 \\
\hline
\end{tabular}


Table A3. Impact of ICT intervention: usefulness, effectiveness and quality of services

\begin{tabular}{llcc}
\hline & & Freq. & Per cent \\
\hline How useful Munna Services are & Very useful & 118 & 16.9 \\
& Useful & 530 & 75.9 \\
& Medium & 48 & 6.9 \\
Speed of services compared to old services & No use & 2 & 0.3 \\
& Total & 698 & 100.0 \\
& Faster & 604 & 86.5 \\
Quality of services compared to old services & Much faster & 90 & 12.9 \\
& No change & 4 & 0.6 \\
& Total & 698 & 100.00 \\
Effect of KHETI on quantity of services & Better & 611 & 87.5 \\
& Far better & 68 & 9.7 \\
& The same & 19 & 2.7 \\
& Total & 698 & 100.0 \\
Quality Index (mean) & Use more agri-advice & 672 & 96.3 \\
& Use less agri-advice & 2 & 0.3 \\
& No difference & 24 & 3.4 \\
\hline Source: Question & Total & 698 & 100.0 \\
& Before intervention & 698 & 0.57 \\
& After intervention & 698 & 0.92 \\
\hline
\end{tabular}

Source: Questionnaire survey 2008 \& 2009.

Table A4. Questions asked to SCPCL/Munnas and speed of answering them

\begin{tabular}{|c|c|c|c|c|}
\hline & \multicolumn{2}{|c|}{ Post-intervention survey } & \multicolumn{2}{|c|}{ Pre-intervention survey } \\
\hline & Freq & Per cent & Freq & Per cent \\
\hline \multicolumn{5}{|l|}{ Frequency of queries } \\
\hline Daily & 3 & 0.43 & 0 & 0.00 \\
\hline Many times in a week & 45 & 6.45 & 0 & 0.00 \\
\hline Once in a month & 8 & 1.15 & 1 & 0.14 \\
\hline Once in a week & 36 & 5.16 & 0 & 0.00 \\
\hline When Needed & 606 & 86.82 & 73 & 10.46 \\
\hline Not asked any question & 0 & 0.00 & 624 & 89.40 \\
\hline Total & 698 & 100.00 & 698 & 100.00 \\
\hline \multicolumn{5}{|l|}{ Speed of answers to the questions } \\
\hline Quick & 258 & 36.96 & 35 & 5.01 \\
\hline 1 day & 217 & 31.09 & 13 & 1.86 \\
\hline 2-4 days & 134 & 19.20 & 6 & 0.86 \\
\hline 5 days or more & 7 & 1.00 & 4 & 0.57 \\
\hline No answer/not asked any question & 82 & 11.75 & 640 & 91.69 \\
\hline Total & 698 & 100.00 & 698 & 100.00 \\
\hline
\end{tabular}

Source: Questionnaire survey 2008 \& 2009. 
Table A5: Impact on access to credit (a material indicator of development), as obtained from a probit model.

\begin{tabular}{|c|c|c|c|}
\hline Variables (dependent variable is access to credit $=1$, otherwise 0 ) & Coefficient & $\begin{array}{l}\text { Standard } \\
\text { error }\end{array}$ & $\begin{array}{l}\text { Marginal } \\
\text { effect }\end{array}$ \\
\hline $\operatorname{KHETI}(=1)$ & $0.546 * * *$ & 0.0911 & 0.2090 \\
\hline Age & 0.0001 & 0.0032 & 0.0000 \\
\hline Own land (ownland) & $0.0658 * * *$ & 0.0153 & 0.0251 \\
\hline Area rent in (Rentin) & $0.0995 * *$ & 0.0431 & 0.0380 \\
\hline Area rent out (Rentout) & 0.0734 & 0.0619 & 0.0280 \\
\hline Tropical livestock unit (Tlu) & -0.0577 & 0.0313 & -0.0221 \\
\hline Farmers' gender (female=1) & -0.0639 & 0.1300 & -0.0246 \\
\hline Farmer has middle school education $=1$ & 0.257 & 0.1510 & 0.0945 \\
\hline Farmer has primary education $=1$ & $0.303 * * *$ & 0.0887 & 0.1140 \\
\hline Farmer has high school and above education $=1$ & 0.211 & 0.2060 & 0.0780 \\
\hline Marital state (married $=1$ ) & -0.136 & 0.1710 & -0.0511 \\
\hline Backward caste $=1$ & 0.155 & 0.1340 & 0.0593 \\
\hline Schedule caste or tribe $=1$ & $0.315^{* *}$ & 0.1390 & 0.1180 \\
\hline Farmers have irrigation facilities $=1$ & 0.207 & 0.1380 & 0.0773 \\
\hline Farmers have agricultural asset $=1$ & 0.048 & 0.1110 & 0.0183 \\
\hline Village has access to bus $=1$ & $0.433 * * *$ & 0.0967 & 0.1680 \\
\hline Village has access to electricity $=1$ & $0.453 * * *$ & 0.1460 & 0.1770 \\
\hline Village economy environment (villagecoprop) & $-0.396 * * *$ & 0.1160 & -0.1510 \\
\hline Constant & $-0.828 * *$ & 0.2810 & \\
\hline LR chi2(18) & 171.03 & & \\
\hline Pseudo R2 & 0.106 & & \\
\hline
\end{tabular}

Notes: $* * *$ significant at 1 per cent, $* *$ significant at 5 per cent, $*$ significant at 10 per cent. Variables are also defined in Table A2. 